\title{
Effects of production, PVT and pipe roughness on multiphase flow correlations in gas wells
}

\author{
Mohamed A. Abd El-Moniem ${ }^{1}$ (1) $\cdot$ Ahmed H. El-Banbi $^{2}$
}

Received: 28 February 2020 / Accepted: 22 June 2020 / Published online: 3 July 2020

(c) The Author(s) 2020

\begin{abstract}
The importance of gas production has increased as gas represents a clean source of energy. We studied different multiphase flow correlations for gas wells. We collected large database for bottomhole flowing pressure for different flow conditions and well configurations. In total, 32 gas wells were selected and our target was to study the effect of multiphase flow correlations input parameters on the accuracy of the predicted pressure drop. Several important multiphase correlations input parameters were selected for this study. These include condensate to gas ratio (CGR) and water to gas ratio (WGR) which represent the production conditions, API and specific gravity of surface gas $\left(V_{\mathrm{g}}\right)$ which represent PVT properties and the tubing roughness $(\varepsilon)$ which represents the tubing condition. Our method was based on changing the values of these selected parameters by a percentage from its original value and determining the new predicted bottomhole flowing pressure. Consequently, we determined the new error compared to the actual measured bottomhole pressure. We performed 352 cases, and we could obtain the effect of the different parameters on both pressure drop calculations and the selection of the best correlation. Guidelines were developed to explain which parameters are more important to be measured accurately for different conditions.
\end{abstract}

Keywords Input data error · Multiphase flow correlations · Gas wells · Nodal analysis

$\begin{array}{llll}\text { Abbreviations } & D & \text { Day } \\ \text { API } & \text { American Petroleum Institute (density } & D & \text { Deviated } \\ & \text { measurement) } & f & \text { Friction factor } \\ \text { BHT } & \text { Bottomhole temperature } & { }^{\circ} \mathrm{F} & \text { Degrees Fahrenheit } \\ \text { CGR } & \text { Condensate gas ratio } & H & \text { High } \\ \text { DE } & \text { Deviation error } & L & \text { Low } \\ \text { DI } & \text { Deviation index } & M & \text { Medium } \\ \text { MAPD } & \text { Mean absolute percent deviation } & m & \text { Mixture } \\ \text { MAPE } & \text { Mean absolute percent error } & n & \text { Number of correlations } \\ \text { MAPE1 } & \text { Mean absolute percent error for maximum error } & P_{\text {wf }} & \text { Bottomhole flowing pressure } \\ \text { MAPE2 } & \text { Mean absolute percent error for the base run } & q_{\mathrm{g}} & \text { Gas flow rate } \\ \text { psi } & \text { Pound force per square inch } & V & \text { Vertical } \\ \text { RE } & \text { Relative error } & v & \text { Velocity } \\ \text { scf } & \text { Standard cubic foot } & \% & \text { Percentage } \\ \text { WGR } & \text { Water gas ratio } & & \\ \text { List of symbols } & \text { Greek letters } \\ \text { bbl } & \text { Barrel } & \rho & \text { Density } \\ d & \text { Diameter } & V_{\mathrm{g}} & \text { Gas specific gravity }\end{array}$

Mohamed A. Abd El-Moniem

eng_mohamedali1986@yahoo.com

1 Amal Petroleum Company, Cairo, Egypt

2 The American University in Cairo, Cairo, Egypt 


\section{Introduction}

Gas reservoirs are one of the most important sources for energy. One of the roles of reservoir and production engineers is to maintain production from gas reservoirs and provide accurate prediction of their performance.

Wells modeling is used to model the different wells to predict the flow under new flow conditions. Nodal analysis is often used for this purpose, which depends on pressure drop calculations in reservoirs, production tubings and flow lines. We will concentrate in this work in studying the pressure drop in the tubing. It is important to have accurate calculations of the pressure drop from the sand face to the well head to provide accurate production forecast. These wells often flow under multiphase conditions of gas, oil and water. The conditions and relative amounts of the different phases change with the life of the well. The pressure drop in the tubing is calculated from different multiphase correlations that have been in use from 1950s till now.

The multiphase flow correlations have been used for many years to calculate the pressure drop in tubing and flow lines. They started with simple modifications of pressure drop calculations for single-phase flow, moved to 2-phase flow correlations that did not take into considerations flow pattern maps or slip velocity, to more sophisticated 2-phase models that accounted for slip and flow pattern maps, to more sophisticated 2- and 3-phase mechanistic models (Ansari et al. 1990).

The problem of multiphase flow appears in the variation of phases that flow through the tubing with different velocities. The idea for each correlation was based on defining some parameters that affect the multiphase flow pressure drop (e.g., mixture properties instead of single-phase properties such as density) and correlate those parameters with the pressure drop. Also, and due to the mixture phenomena, new parameters have appeared like slippage, holdup and flow patterns to accurately predict the pressure drop resulting from multiphase flow.

Fluid properties furnish an important input to multiphase flow correlations, and therefore the most significant PVT parameters deserve a cursory review.

The calculation of pressure drop will depend on the mixture of gas and liquid in the case of multiphase as follows

1. $\rho=\rho_{\mathrm{m}}$ "density of mixture of gas + liquid"

2. $v=v_{\mathrm{m}}$ "velocity of mixture"

3. $f=f \mathrm{~m}$ "friction factor for flow of gas and liquid"

The different multiphase correlations can be categorized into empirical correlations and mechanistic models. The empirical correlations are divided into three categories according to slip phenomenon and flow regimes.
The first set of correlations was developed by some investigators with the assumption of no slip between gas and liquid (i.e., gas and oil flow at same velocity) and no flow patterns. Fancher and Brown (1963) correlation is an example of these types of correlations. The second set of correlations was developed to include slip phenomenon but ignore flow patterns [e.g., Hagedorn and Brown $(1964,1965)$ correlation]. The third type of empirical correlations considers both the slip phenomenon and flow regimes [e.g., Beggs and Brill (1973) correlation]. The mechanistic models, however, incorporate more of physics than merely models based on observed data [e.g., Ansari et al. (1990)].

All correlations are derived from the general energy equation:

$\left(\frac{\mathrm{d} P}{\mathrm{~d} L}\right)_{t}=\left(\frac{\mathrm{d} P}{\mathrm{~d} L}\right)_{\text {elevation }}+\left(\frac{\mathrm{d} P}{\mathrm{~d} L}\right)_{\text {acceleration }}+\left(\frac{\mathrm{d} P}{\mathrm{~d} L}\right)_{\text {friction }}$

So, different studies have been done to develop either a new empirical correlation or a mechanistic model. Abd El-Moniem and El-Banbi (2018) studied the effect of data errors on different multiphase flow correlations for oil wells, but no clear work for the effect of each input parameter on the different correlations for gas wells. In this work, we studied the effect of some important parameters on the pressure drop calculation from fourteen multiphase flow correlations for gas wells that produce under multiphase flow conditions. The fourteen correlations are:

1. Duns and Ros Original (1963)

2. Duns and Ros Modified

3. Gray (1978)

4. Hagedorn and Brown $(1964,1965)$

5. GRE (1994)

6. Mukerjee and Brill (1983)

7. Beggs and Brill (1973)

8. Hydro 3P

9. Orkiszewski (1967)

10. Petroleum Experts (2013)

11. Petroleum Experts 2 (2013)

12. Petroleum Experts 3 (2013)

13. Petroleum Experts 4 (2013)

14. Petroleum Experts 5 (2013).

Table 1 Criteria used for the classification for gas wells

\begin{tabular}{llll}
\hline Classification & $q_{\mathrm{g}}$ "MMscf/D" & $\begin{array}{l}\text { CGR "STB/ } \\
\text { MMscf" }\end{array}$ & $\begin{array}{l}\text { WGR } \\
\text { "STB/ } \\
\text { MMscf" }\end{array}$ \\
\hline Low & $<10$ & $<30$ & $<10$ \\
Medium & $10-50$ & $30-70$ & $10-50$ \\
High & $>50$ & $>70$ & $>50$ \\
\hline
\end{tabular}


Table 2 Range of gas well data used in this study

\begin{tabular}{lc}
\hline Gas wells & \\
\hline Property & Range \\
\hline$q_{\mathrm{g}}, \mathrm{MMscf} / \mathrm{D}$ & $0.53-101$ \\
CGR, STB/MMscf & $0-317$ \\
WGR, STB/MMscf & $0-1457$ \\
Condensate gravity, ${ }^{\mathrm{o}}$ API & $44-67$ \\
$\gamma_{\mathrm{g}}$ & $0.57-1.1$ \\
$P_{\mathrm{wf}}, \mathrm{psi}$ & $705-10,075$ \\
\hline
\end{tabular}

$\overline{7}$

Table 3 Classification of different model runs

\begin{tabular}{|c|c|c|c|c|}
\hline Run number & Rate & CGR & WGR & $\begin{array}{l}\text { Well } \\
\text { geom- } \\
\text { etry }\end{array}$ \\
\hline 1 & $\mathrm{~L}$ & $\mathrm{~L}$ & $\mathrm{~L}$ & $\mathrm{~V}$ \\
\hline 2 & & & & $\mathrm{D}$ \\
\hline 3 & & & M & V \\
\hline 4 & & & & $\mathrm{D}$ \\
\hline 5 & & & $\mathrm{H}$ & $\mathrm{V}$ \\
\hline 6 & & & & $\mathrm{D}$ \\
\hline 7 & & M & $\mathrm{L}$ & $\mathrm{V}$ \\
\hline 8 & & & & $\mathrm{D}$ \\
\hline 9 & & & M & V \\
\hline 10 & & & $\mathrm{H}$ & V \\
\hline 11 & & & & $\mathrm{D}$ \\
\hline 12 & & $\mathrm{H}$ & $\mathrm{L}$ & $\mathrm{V}$ \\
\hline 13 & & & & $\mathrm{D}$ \\
\hline 14 & & & M & V \\
\hline 15 & & & & $\mathrm{D}$ \\
\hline 16 & & & $\mathrm{H}$ & $\mathrm{V}$ \\
\hline 17 & & & & $\mathrm{D}$ \\
\hline 18 & M & $\mathrm{L}$ & $\mathrm{L}$ & $\mathrm{V}$ \\
\hline 19 & & & & $\mathrm{D}$ \\
\hline 20 & & & M & V \\
\hline 21 & & & & $\mathrm{D}$ \\
\hline 22 & & M & $\mathrm{L}$ & V \\
\hline 23 & & & & $\mathrm{D}$ \\
\hline 24 & & $\mathrm{H}$ & $\mathrm{L}$ & $\mathrm{V}$ \\
\hline 25 & & & & $\mathrm{D}$ \\
\hline 26 & & & M & V \\
\hline 27 & & & & $\mathrm{D}$ \\
\hline 28 & & & $\mathrm{H}$ & $\mathrm{D}$ \\
\hline 29 & $\mathrm{H}$ & $\mathrm{L}$ & $\mathrm{L}$ & V \\
\hline 30 & & & & $\mathrm{D}$ \\
\hline 31 & & & M & V \\
\hline 32 & & $\mathrm{H}$ & $\mathrm{L}$ & D \\
\hline
\end{tabular}

Table 4 Classification of different model runs for vertical wells

\begin{tabular}{lllll}
\hline Run number & Rate & CGR & WGR & $\begin{array}{l}\text { Well } \\
\text { geom- } \\
\text { etry }\end{array}$ \\
\hline 1 & L & L & L & V \\
2 & & & M & V \\
3 & & M & L & V \\
4 & & & M & V \\
5 & & H & V \\
6 & & L & V \\
7 & & & M & V \\
8 & & & H & V \\
9 & M & L & L & V \\
10 & & & M & V \\
11 & & M & L & V \\
12 & & H & L & V \\
13 & & & M & V \\
14 & & L & M & V \\
15 & H & & & \\
16 & & & & \\
\hline
\end{tabular}

Table 5 Classification of different model runs for deviated wells

\begin{tabular}{|c|c|c|c|c|}
\hline Run number & Rate & CGR & WGR & $\begin{array}{l}\text { Well } \\
\text { geom- } \\
\text { etry }\end{array}$ \\
\hline 1 & $\mathrm{~L}$ & $\mathrm{~L}$ & $\mathrm{~L}$ & $\mathrm{D}$ \\
\hline 2 & & & M & $\mathrm{D}$ \\
\hline 3 & & & $\mathrm{H}$ & $\mathrm{D}$ \\
\hline 4 & & M & $\mathrm{L}$ & $\mathrm{D}$ \\
\hline 5 & & & $\mathrm{H}$ & $\mathrm{D}$ \\
\hline 6 & & $\mathrm{H}$ & $\mathrm{L}$ & $\mathrm{D}$ \\
\hline 7 & & & M & $\mathrm{D}$ \\
\hline 8 & & & $\mathrm{H}$ & $\mathrm{D}$ \\
\hline 9 & M & $\mathrm{L}$ & $\mathrm{L}$ & $\mathrm{D}$ \\
\hline 10 & & & M & $\mathrm{D}$ \\
\hline 11 & & M & $\mathrm{L}$ & $\mathrm{D}$ \\
\hline 12 & & $\mathrm{H}$ & $\mathrm{L}$ & $\mathrm{D}$ \\
\hline 13 & & & M & $\mathrm{D}$ \\
\hline 14 & & & $\mathrm{H}$ & $\mathrm{D}$ \\
\hline 15 & $\mathrm{H}$ & $\mathrm{L}$ & $\mathrm{L}$ & $\mathrm{D}$ \\
\hline 16 & & $\mathrm{H}$ & $\mathrm{L}$ & D \\
\hline
\end{tabular}




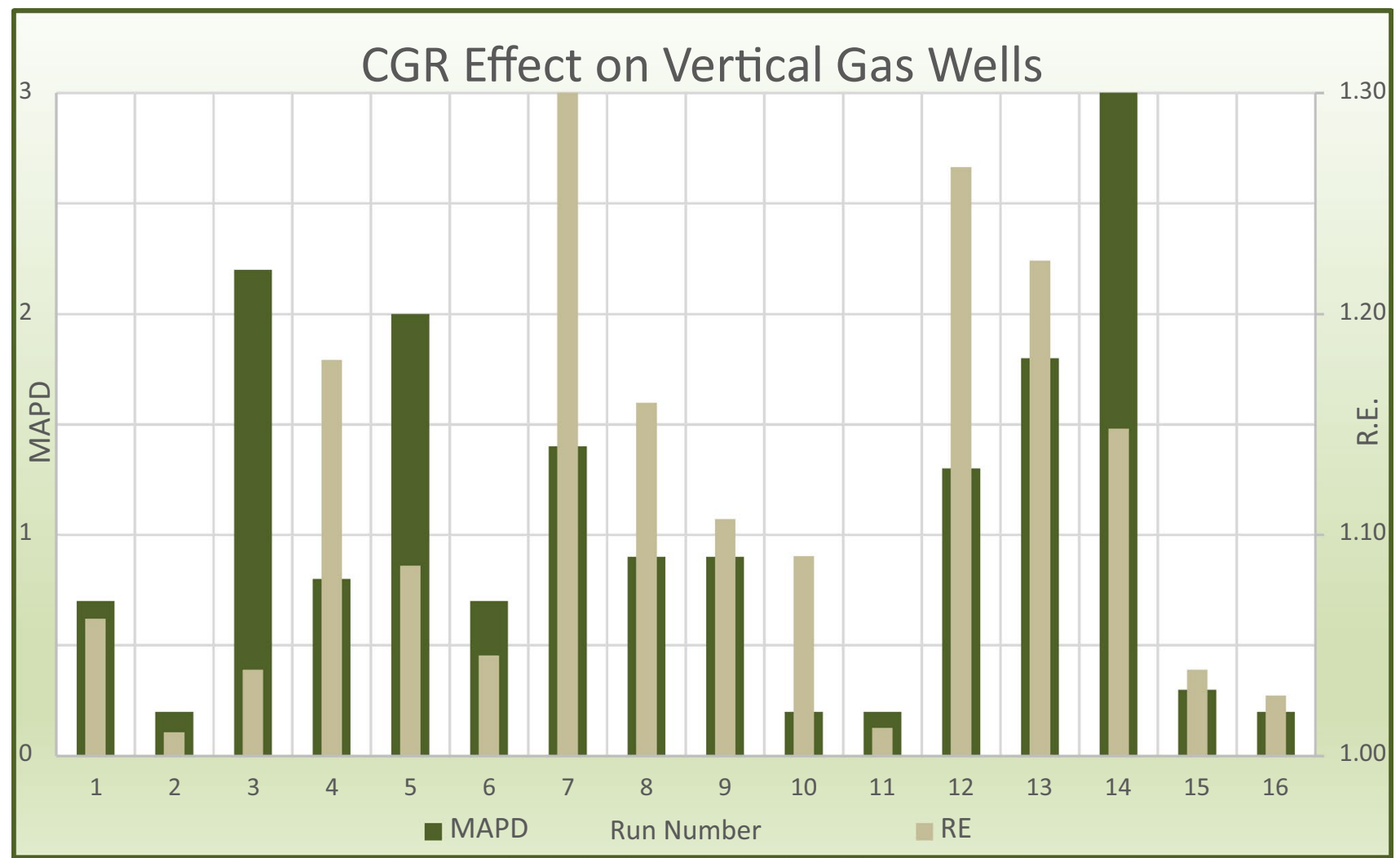

Fig. 1 Effect of CGR on vertical wells using MAPD and RE methods

The different input parameters used in the pressure drop calculations can be classified into three categories:

\section{Production conditions like CGR and WGR}

2. Fluid properties like API of the condensate and the gas specific gravity

3. The tubing roughness that represents the tubing condition.

To have a good prediction of the pressure drop calculation, the different input parameters should be measured accurately. The work on this study depends on the hypothesis of having an error in the measurements of the input parameters by a percentage from the actual data. The target is to indicate the effect of each parameter on the pressure drop calculations using the different multiphase flow correlations. We worked on comparing the different results using different methods as will be explained later. We quantified (based on comparisons with actual well data) which parameters have the highest impact on correlations calculated pressure drop at different flow conditions and well configurations. One of the parameter used in this study is the tubing roughness which reflects the tubing condition. Tubing roughness is not a measurable parameter, and common values are usually used in the wells modeling. One of the findings of this study is the effect of this parameter on the pressure drop calculation. We could identify the flowing conditions that affect the pressure drop significantly.

The different results from this study will give the readers guidelines for the different parameters effects on the pressure drop calculations.

\section{Methodology}

In this work, the effect of the input data errors on different multiphase flow correlations for gas wells will be studied. The different wells produce water and condensate associated with gas. The following explains the detailed methodology followed in this work.

\section{Data collection}

A large database of bottomhole flowing pressure points has been collected by Abd El-Moniem and El-Banbi (2015, 2018a, b), Abd El-Moniem (2016) from both the literature from Poettmann and Carpenter (1952), Baxendell and Thomas (1961), Aziz and Govier (1972), Chierici et al. (1974), Ashiem (1986), Minami and Brill (1987), Reinicke and Remer (1987), and Peffer et al. (1988) and other actual 


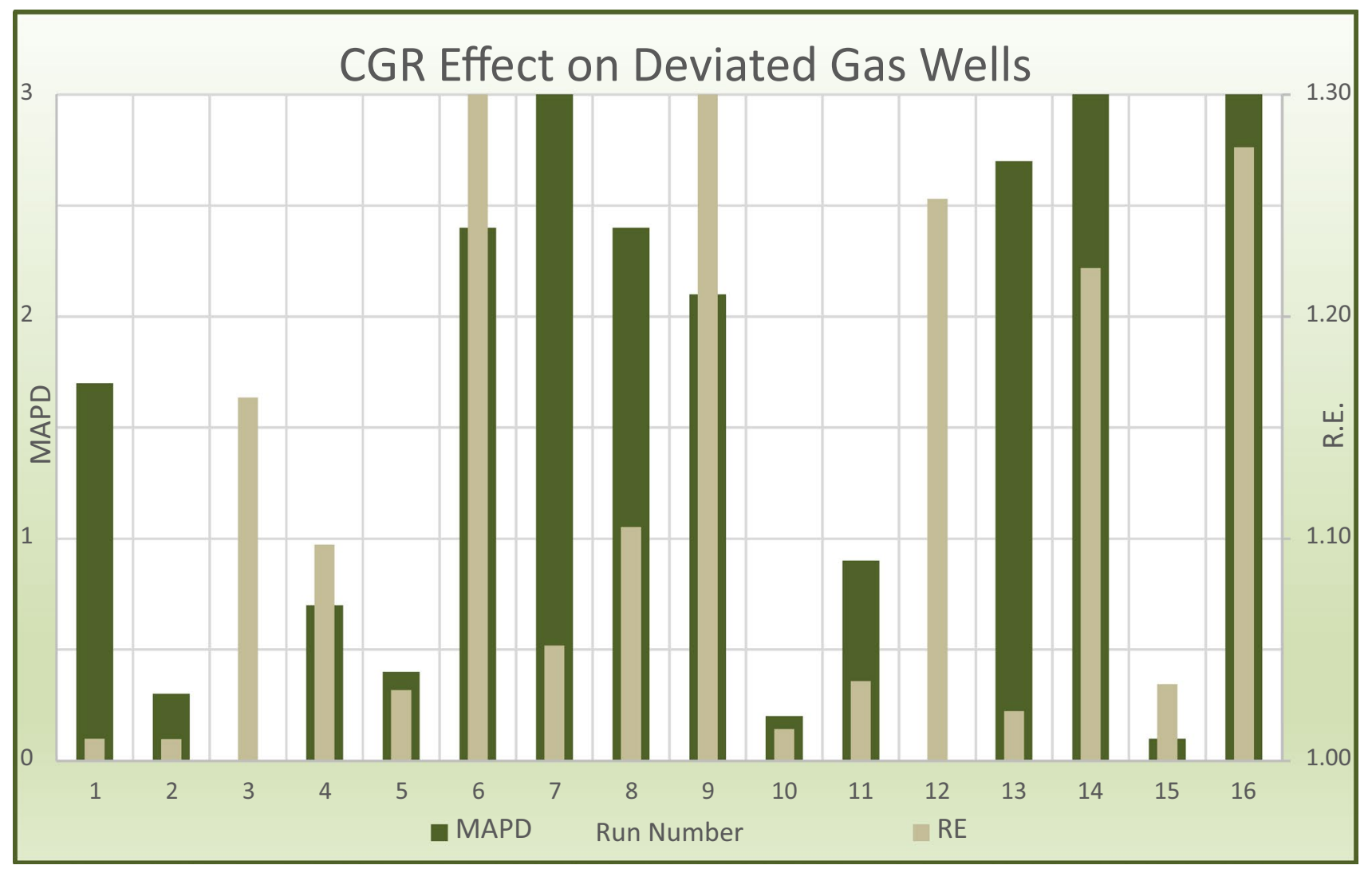

Fig. 2 Effect of CGR on deviated wells using MAPD and RE methods

data. Quality check for all the collected data has been done to assure its validity to be used in the study. We excluded any misleading data. Then, a commercial software (2013) was used to calculate the pressure drop in the tubing from the sandface to the well head for all data points (close to 1000 measured pressure points). The data points were divided into groups based on an arbitrary classification covering different flow conditions and well configurations.

Table 1 shows the classification of data based on flow conditions. Another classification was done based on well configurations.

Thirty-two gas wells were selected for this study. The wells were selected to cover different flow conditions for both vertical and deviated holes. Table 2 shows the range of data used in this study for gas wells.

\section{Models construction}

Different well models were constructed, and bottomhole pressure was calculated for each well using 14 different multiphase flow correlations. The calculated bottomhole pressure was compared with actual measured pressures, and an error value was calculated for every point using:
Error $(\%)=\frac{\text { Predicted }- \text { Actual }}{\text { Actual }} * 100$

At this step, the error from the 14 different correlations was calculated for the 32 base runs.

The second step was to study the effect of changing some parameters on different multiphase flow correlations. The values of production data parameters (CGR and WGR) were changed by $\pm 20 \%$ and PVT data (API and $\gamma_{\mathrm{g}}$ ) by $\pm 10 \%$ from their original values. These percentages were selected to represent average errors in the respective measurements. For tubing roughness, we used three values recommended by different commercial software programs.

After changing the selected parameters, two new values for each parameter were calculated, and following the same steps for the calculation of the error resulted from the different correlations, we could perform 320 new cases for the 32 wells.

Table 3 shows the classification of the run numbers for the 32 wells according to different flow conditions for both vertical and deviated wells where $\mathrm{L}$ represents low, $\mathrm{M}$ for medium, $\mathrm{H}$ for high, $\mathrm{V}$ for vertical and $\mathrm{D}$ for deviation; moreover, Tables 4 and 5 show the run number for each 16 
wells according to different flow conditions for both vertical and deviated wells, respectively.

\section{Methods used to determine the effect of each parameter}

Three methods were used to determine the effect of each input parameter on the pressure drop calculations for the different multiphase correlations. The details of these evaluations are given in the following paragraphs.

\section{Effect of input parameters on the selection of the best correlation used in the prediction of the pressure drop calculation}

After selecting the best correlation from the base run (the correlation which gave the lowest error), the best correlation for the two perturbed runs was determined. The assumption here is that if the best correlation is changed in the two perturbed runs, then the input parameter is considered to have high effect on the pressure drop calculations. Similarly, if the best correlation does not change in the two perturbed runs, the input parameter is considered to have a small effect. The input parameter will be considered to have medium effect if the perturbation runs result in changing the best correlation in only one of the two runs.

\section{Effect of input parameters on the calculated absolute error based on the best correlation obtained from the base run}

In this method, the effect of the selected input parameter on the absolute error of the best correlation obtained from the base run was investigated. The deviation error (DE) of the two perturbed runs from the base run was calculated according to:

$\mathrm{DE}=\left(\text { Error }_{\text {Perturbed Run }}-\text { Error }_{\text {Base Run }}\right)_{\text {for best correlation from base run }}$

Then the mean absolute percent deviation (MAPD) for the DE was calculated from:

MAPD $=\frac{\mathrm{DE}_{\text {for Positive perturbed run }}+\mathrm{DE}_{\text {for Negative perturbed run }}}{2}$

We considered that if MAPD is less than 0.5, the selected input parameter will have low effect. However, MAPD

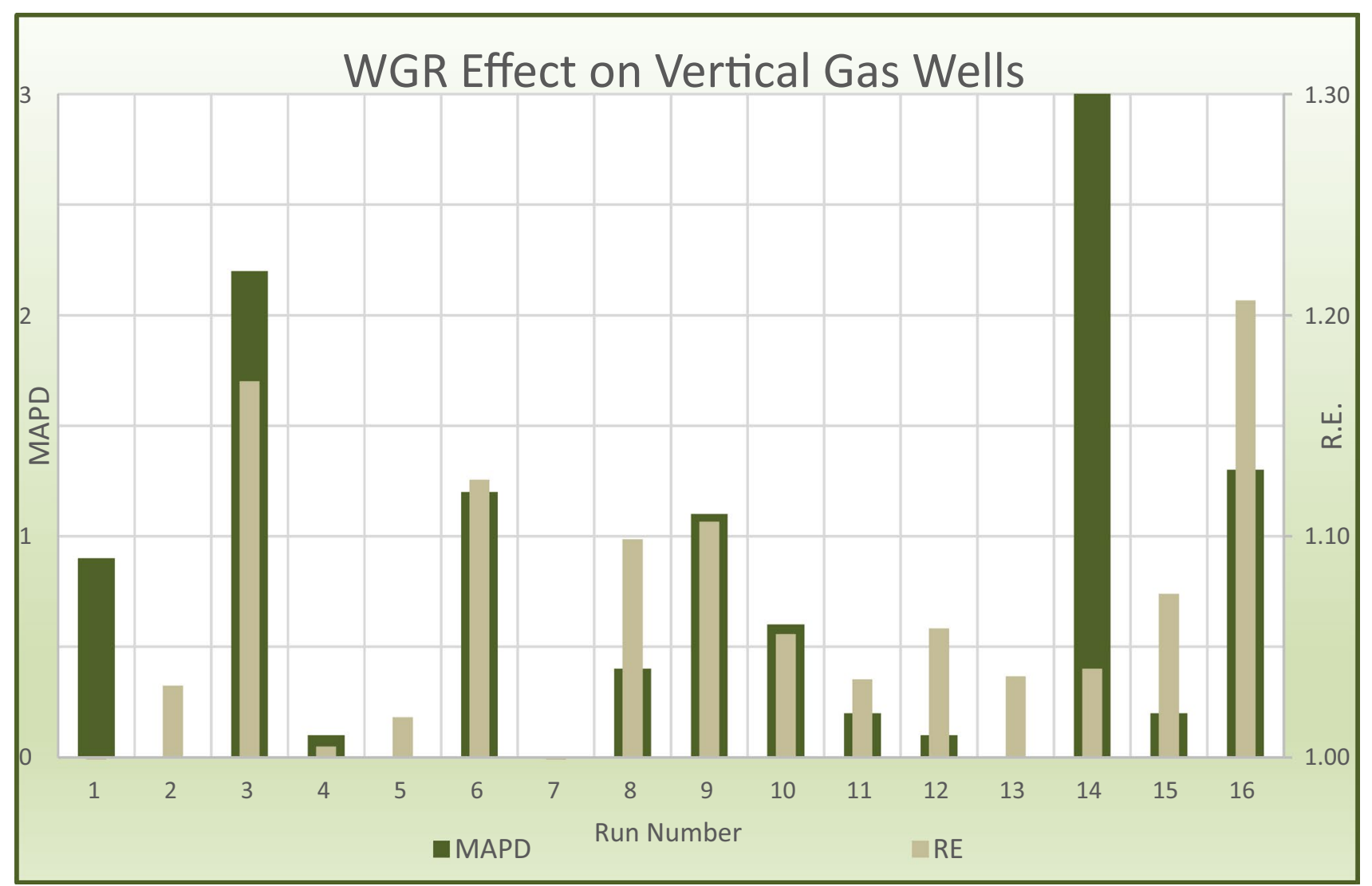

Fig. 3 Effect of WGR on vertical wells using MAPD and RE methods 


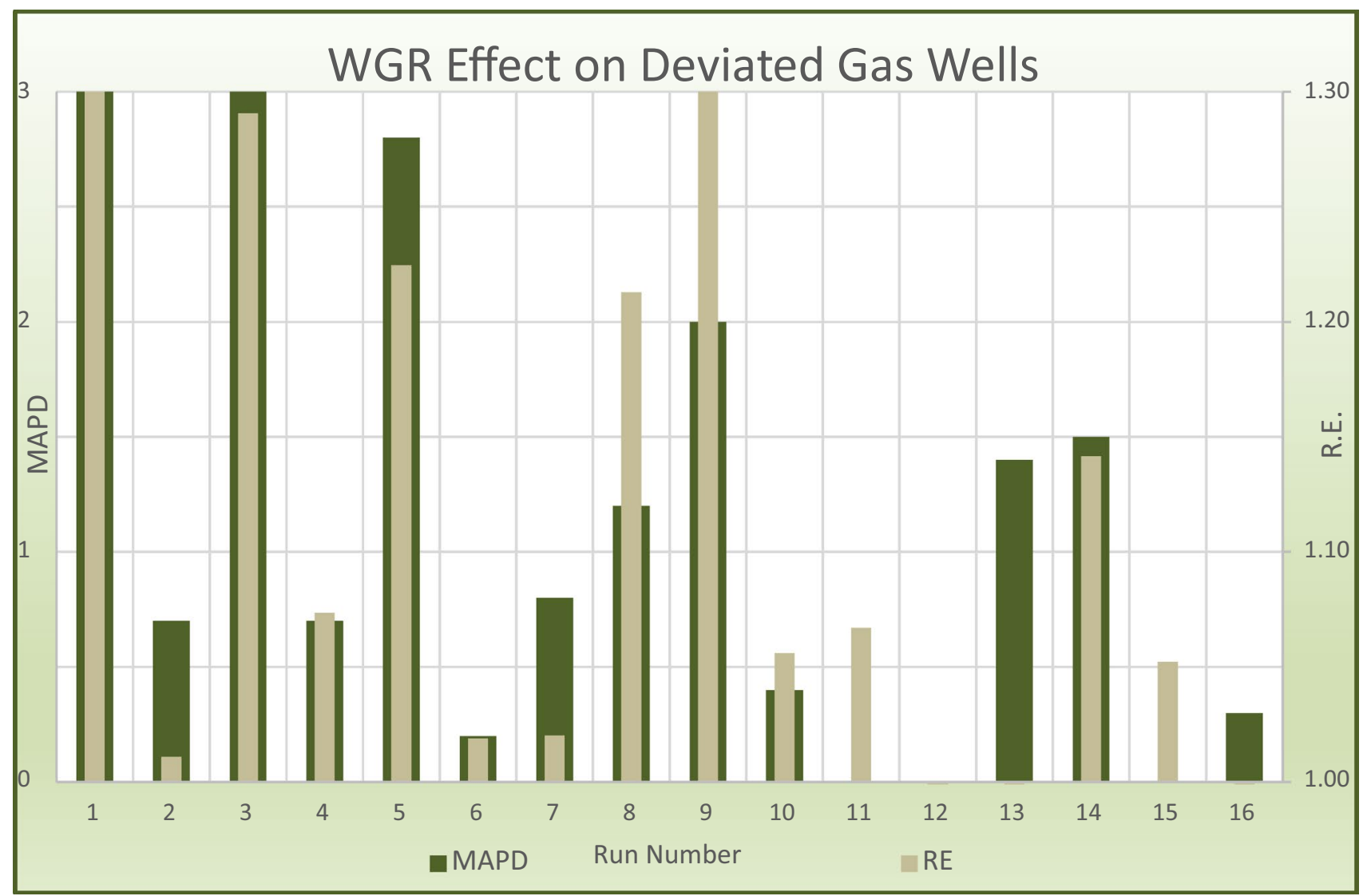

Fig. 4 Effect of WGR on deviated wells using MAPD and RE methods

between 0.5 to 2 is considered medium, and above 2 is considered high effect.

\section{Effect of input parameters on the maximum absolute error from each correlation relative to actual data}

The last evaluation method is based on the calculation of the maximum error resulting from the two perturbed runs and its relation to the base run and actual data. The maximum value of error from each correlation of the two perturbed runs was obtained, and then, the mean absolute percent error for the maximum error values for all the 14 correlations was calculated by:

MAPE1 $=\frac{\sum_{i=1}^{n} \text { Maximum Absolute Percent } \text { Error }_{\text {from perturbed runs }}}{n}$

$n=14$ (total number of correlations used in the study)

Then, the mean absolute percent error for all the multiphase flow correlations of the base run was calculated by:
MAPE2 $=\frac{\sum_{i=1}^{n} \text { Absolute Percent } \text { Error }_{\text {Base run }}}{n}$

Then, a qualitative indicator (relative error) is obtained from:

$\mathrm{RE}=\frac{\text { MAPE1 }}{\text { MAPE2 }}$

The relative error term is used to find the relation between the actual data and the error from the base run and the maximum error from the perturbed runs.

It is assumed that if RE is less than 1.1, the selected input parameter will have low effect. The input parameter will have medium effect if the RE is between 1.1 and 1.2 and high effect if RE is higher than 1.2. 


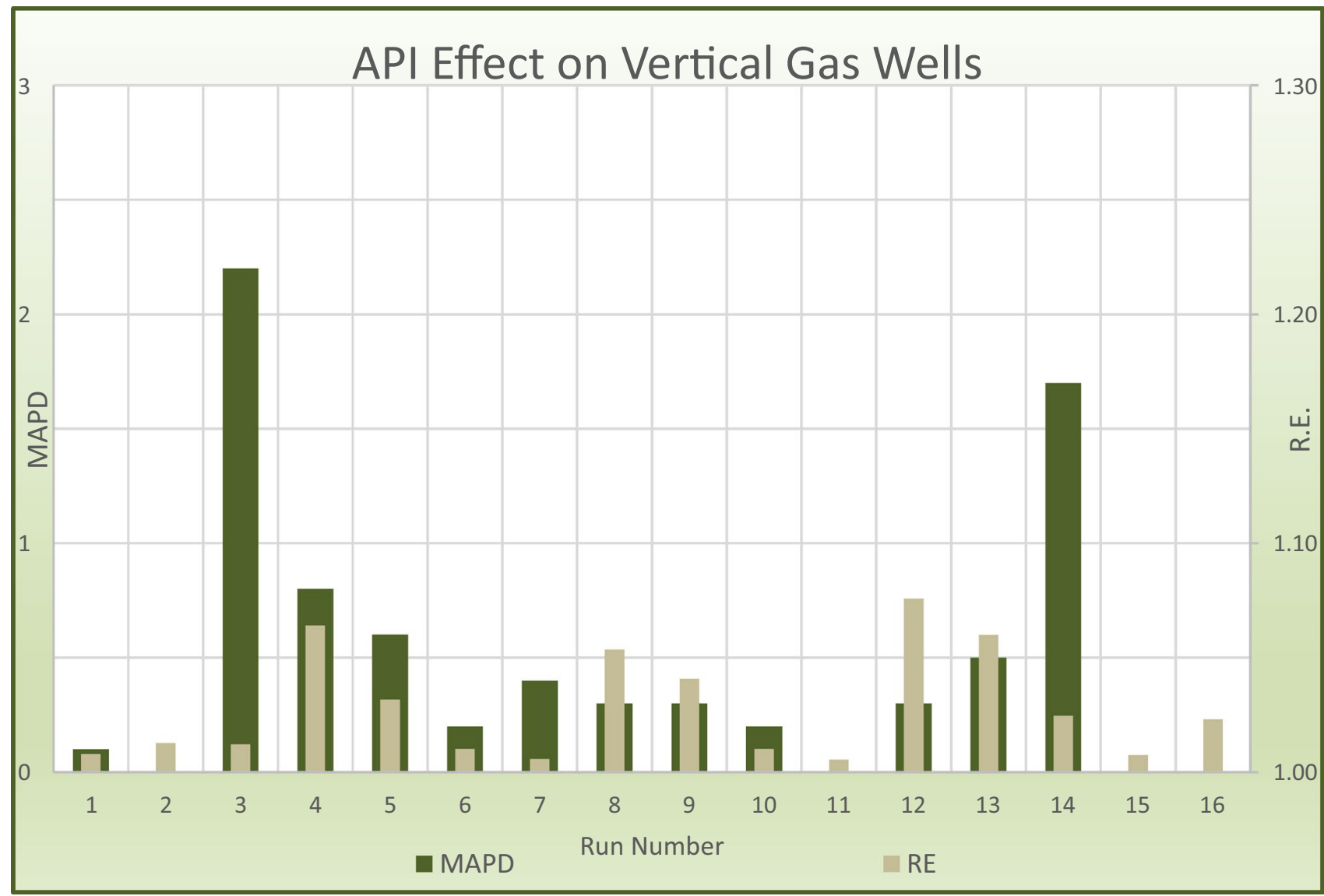

Fig. 5 Effect of API on vertical wells using MAPD and RE methods

\section{Sensitivity analysis on the different input parameters}

Five important input parameters were subjected to the error analyses explained above to derive guidelines for their relative importance on multiphase flow correlations calculations. These five parameters are condensate gas ratio (CGR), water gas ratio (WGR), API gravity of the oil, specific gravity of the produced gas and tubing roughness. For each of the five input parameters, the three techniques for investigating their effects on the multiphase pressure drop calculations were used as explained in the following:

\section{Effect of input parameter on the selection of the best correlation used in the prediction of the pressure drop calculation}

It was found that after changing CGR up to $\pm 20 \%$ from the actual values, the error in input CGR has low effect on changing the best correlation for most cases. However, CGR value has high to medium effect on the selection of best multiphase correlation for gas wells with low WGR.

To test the effect of WGR, its input values were changed up to $\pm 20 \%$ from the actual data. It was found that error (as high as 20\%) in WGR has low effect on the selection of the best multiphase flow correlation in most cases. Moreover, changing API up to $\pm 10 \%$ from the actual data has low effect in most cases regardless of the flow rate, fluid fractions (CGR and WGR) and tubing configuration. Also, gas specific gravity has low effect on changing the best correlation when the error in its value is within $\pm 10 \%$. It has medium to high effect on gas wells with low WGR and at any gas production rate.

Finally, tubing roughness was found to have low effect in low gas rate wells, but medium to high effect on changing the best correlation in high gas rate wells. 


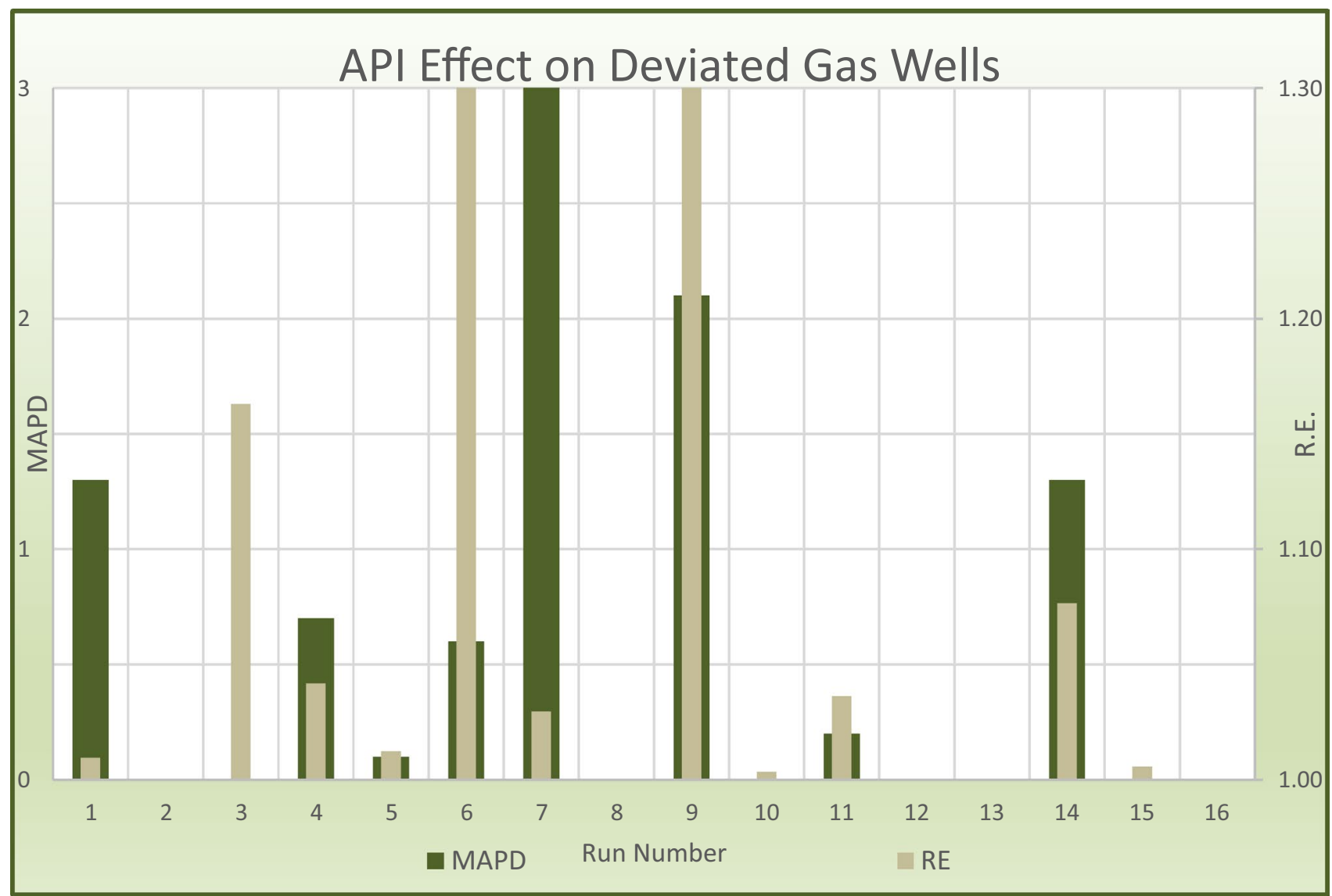

Fig. 6 Effect of API on deviated wells using MAPD and RE methods

\section{Effect of input parameter on the calculated absolute error based on the best correlation obtained from the base run}

It was found that after changing CGR up to $\pm 20 \%$ from the actual data, CGR has high to medium effect in most cases, but has low effect in high gas rate wells as shown in Figs. 1 and 2 .

Figures 3 and 4 show that changing input WGR up to $\pm 20 \%$ from the actual data has high to medium effect in most cases. API was found to have low to medium effect when it is changed by up to $\pm 10 \%$ from the actual data as shown in Figs. 5 and 6.

Figures 7 and 8 show that gas specific gravity (when changed with $\pm 10 \%$ from the actual data) has high to medium effect in most cases. Tubing roughness, again, has low effect in low gas production rate wells. However, it has medium to high effect in high and medium gas rate wells with low WGR as shown in Figs. 9 and 10.

\section{Effect of input parameter on the maximum absolute error from each correlation relative to actual data}

It was found that changing the input CGR up to $\pm 20 \%$ from the actual data, the CGR has low effect in most cases except gas wells with high CGR and low WGR, where it was found to have high effect (Figs. 1 and 2).

Figures 3 and 4 show that changing WGR up to $\pm 20 \%$ from the actual data is found to have low effect in most cases with vertical wells and high effect in most cases with deviated wells.

It was found that changing API, by $\pm 10 \%$ from the actual data, has low effect in most cases as shown in Figs. 5 and 6. Similar to the effect of gas specific gravity on the calculated absolute error for the best correlation, it also has medium to high effect on the maximum absolute error for each correlation relative to the actual data. This was found by perturbing the values of gas specific gravity within $\pm 10 \%$ of the actual data as shown in (Figs. 7 and 8). 


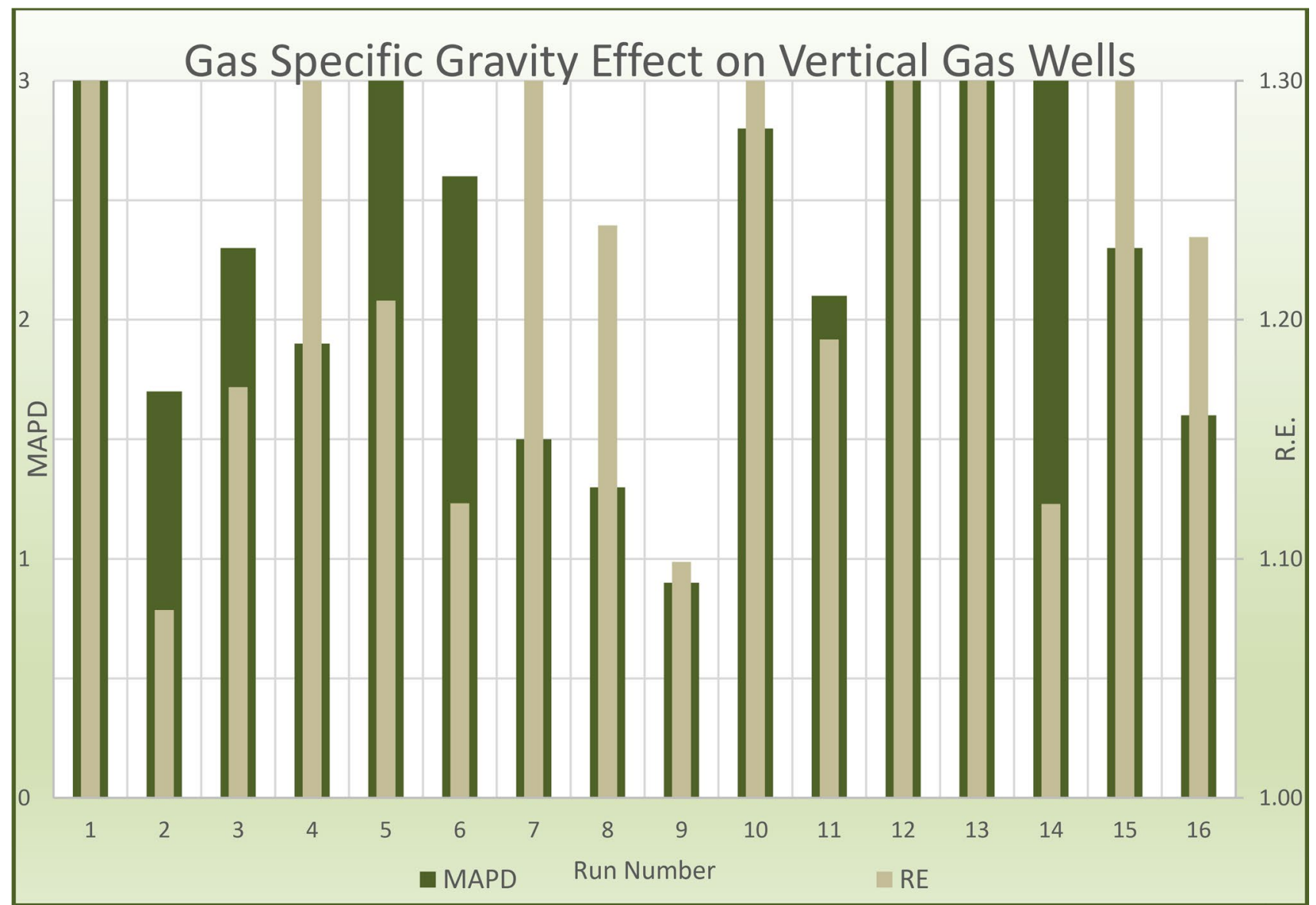

Fig. 7 Effect of gas specific gravity on vertical wells using MAPD and RE methods

Finally, toughness has low effect in most cases except cases with high gas rate wells and cases with medium gas rate with low WGR, where the effect is high and medium, respectively, as shown in Figs. 9 and 10.

\section{Results}

\section{Effect of input parameters on the selection of the best correlation used in the prediction of the pressure drop calculation}

Table 6 summarizes the results of all five input parameters in a variety of gas production rate, CGR and WGR levels. The red color denotes high effect, orange for medium effect, green for low effect and black for unavailable data. The table shows that for many cases, the effect of error in these input parameters does not change the best correlation. The main exception to that general observation is gas specific gravity which was found to change the best correlation in some cases shown in the table.
The results summarizing the effects of the different input parameters are given in percentages in Table 9. The percentages clearly show that the error in gas specific gravity has the highest impact on both the selection of the best multiphase flow correlation and the errors in pressure drop calculations. Following the gas specific gravity, tubing roughness comes next in importance.

\section{Effect of input parameters on the calculated absolute error based on the best correlation obtained from the base run}

Table 7 summarizes the effect of different input parameters on the calculated absolute error of the best correlation for the base run. Gas specific gravity, $\gamma_{\mathrm{g}}$, is considered the most effective parameter on the pressure drop calculations for gas wells. Tubing roughness has low to medium effect in a variety of conditions of gas production rate, CGR and WGR.

Table 9 shows the percentage of all parameters and their effect on the accuracy (error) of the best multiphase flow correlations. Error in gas specific gravity has the highest effect on the error of the best multiphase flow correlation. 


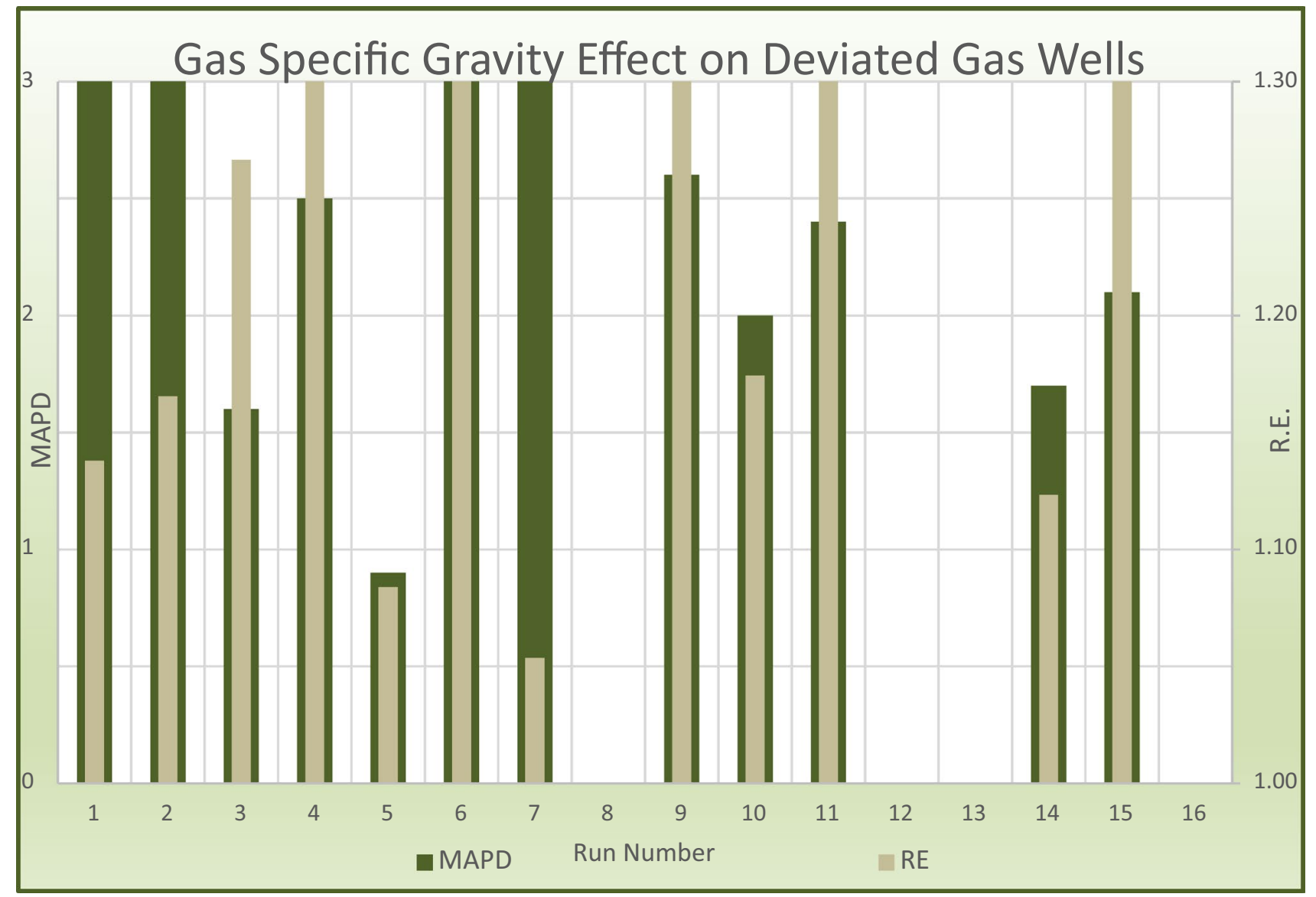

Fig. 8 Effect of gas specific gravity on deviated wells using MAPD and RE methods

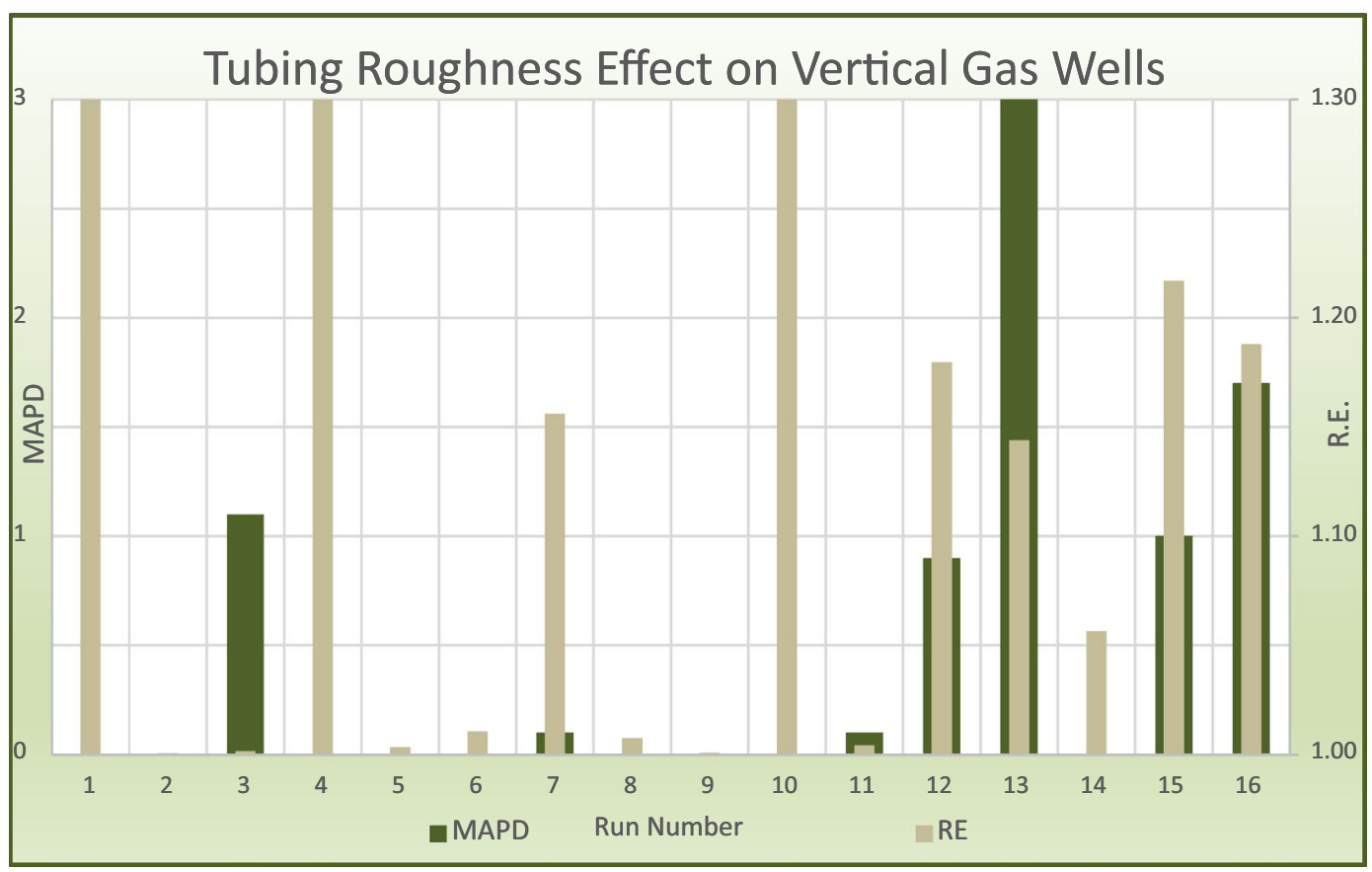

Fig. 9 Effect of tubing roughness on vertical wells using MAPD and RE methods 


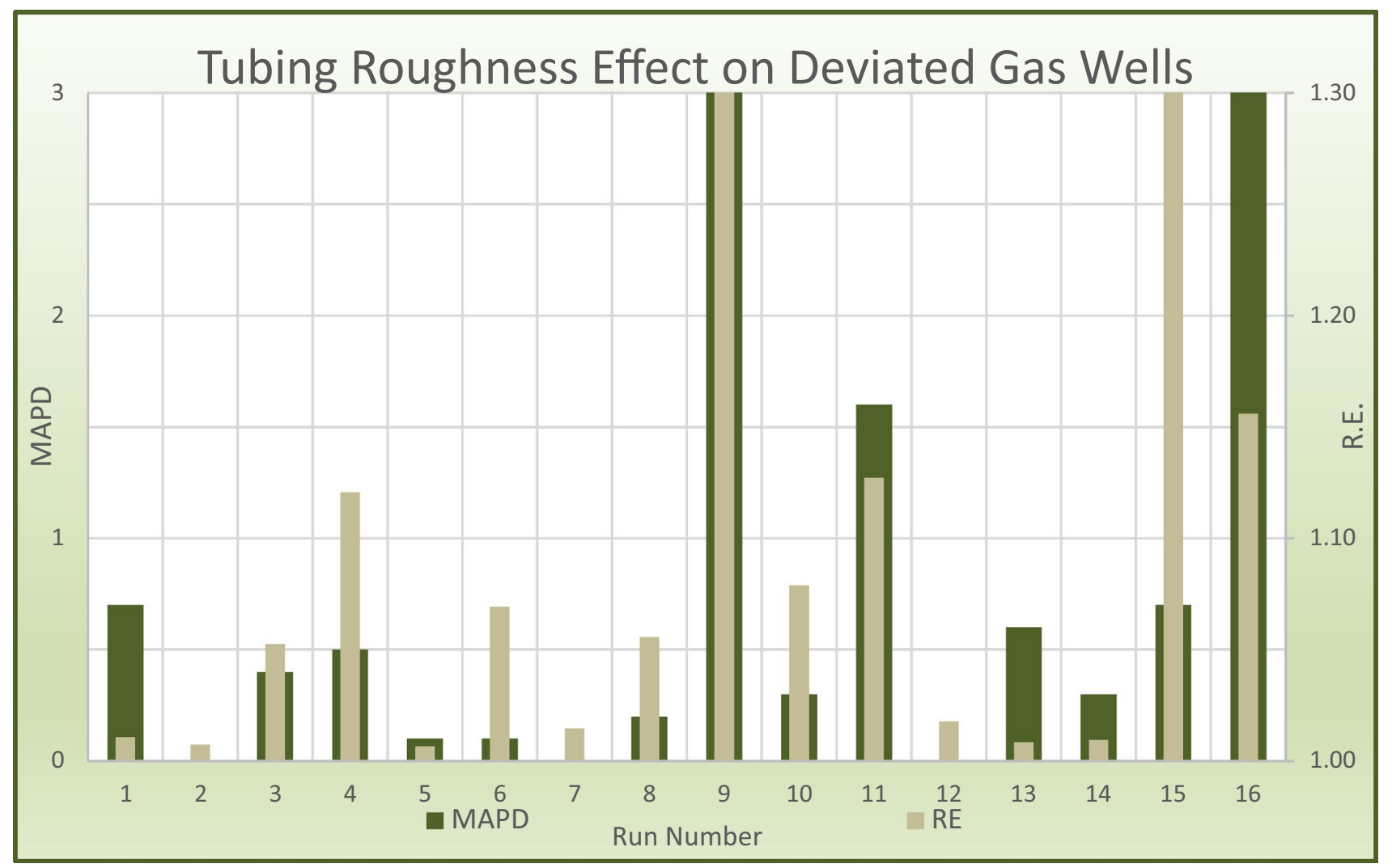

Fig. 10 Effect of tubing roughness on deviated wells using MAPD and RE methods

Other input parameters affect the results of the correlation calculations, but to a lesser degree.

\section{Effect of input parameters on the maximum absolute error from each correlation relative to actual data}

Table 8 shows that the most important input parameter affecting the results of the all correlations accuracy is the gas specific gravity. The color-coded results in Table 8 show that the red color (denoting high impact of the error in input data to the accuracy of the multiphase flow predicted results) appears in many significant locations covering the ranges of high and low gas production rate, high and low CGR, and high WGR.

In Table 9, the percentages of all input parameters and their effect on the different multiphase flow correlations are shown. The results show that error in gas specific gravity has significant effects on the accuracy of multiphase flow correlations. This is followed by errors in tubing roughness and CGR.

\section{Discussion of results}

The new methods in the field of multiphase flow focus on developing either new mechanistic models, new correlations or developing artificial intelligence models to predict the bottomhole flowing pressure. In this work, the effect of different input parameters used in different multiphase flow correlation calculations was investigated. As mentioned in Table 2, a wide range of production data was used to cover different flow conditions with different gas types (dry, wet and retrograde gas condensate). The 32 gas wells used in the study produced with gas flow rate ranging from 0.5 to 101 MMscf/D with wide range of condensate production. The CGR ranged from 0 (dry gas) to 317 STB/MMscf (rich retrograde condensate). We studied the effect of water production also since the range of the ratio of water produced with gas varied from 0 (no water production) to 1457 STB/MMscf (high water production). Wide range of gas and condensate specific gravities was also considered. Gas specific gravity ranged between 0.57 and 1.1, and condensate gravity ranged between 44 and $67{ }^{\circ} \mathrm{API}$. The wide range of the data used in this study makes it applicable for most flow conditions. 
Table 6 Effect of changing input parameters on the selection of best correlation

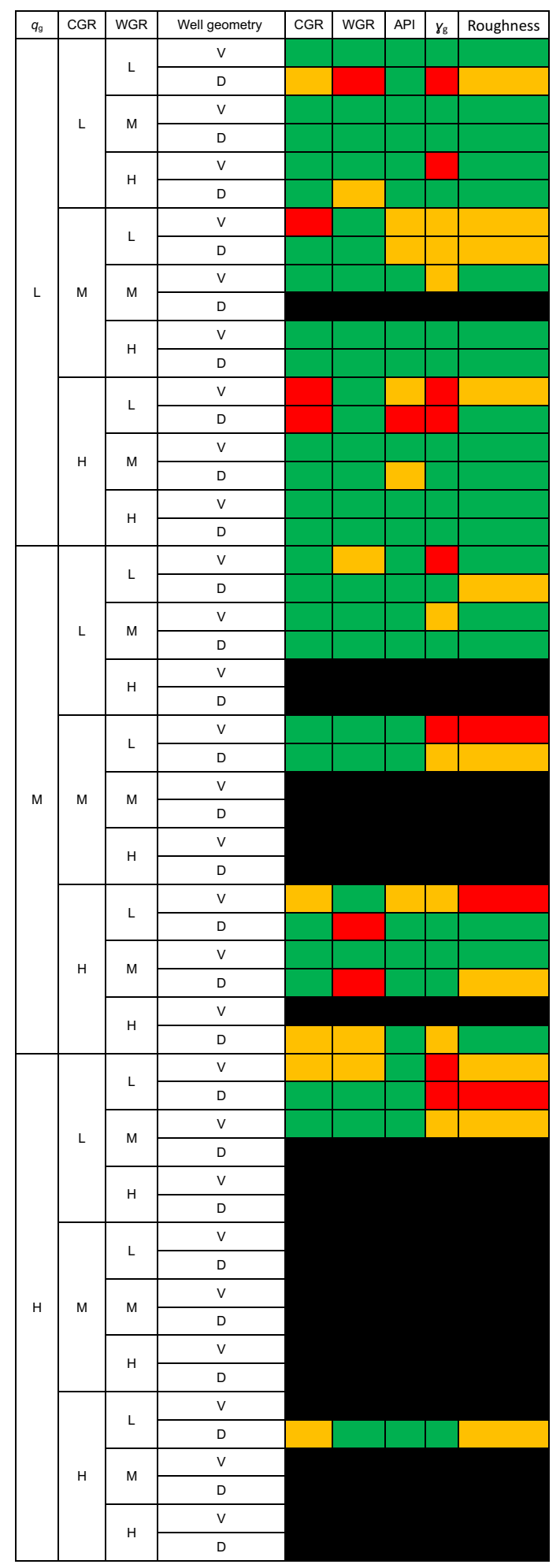

Table 7 Effect of changing input parameters on the MAPD

\begin{tabular}{|c|c|c|c|c|c|c|c|c|}
\hline$q_{9}$ & CGR & WGR & Well geometry & CGR & WGR & API & $\gamma_{g}$ & Roughness \\
\hline \multirow{18}{*}{$\mathrm{L}$} & \multirow{6}{*}{ L } & \multirow{2}{*}{ L } & v & 0.7 & 0.9 & 0.1 & 3.2 & 0 \\
\hline & & & D & 1.7 & 24 & 1.3 & 7.7 & 0.7 \\
\hline & & \multirow{2}{*}{ M } & v & 0.2 & 0 & 0 & 1.7 & 0 \\
\hline & & & D & 0.3 & 0.7 & 0 & 3.8 & 0 \\
\hline & & \multirow{2}{*}{$\mathrm{H}$} & v & 2.2 & 2.2 & 2.2 & 2.3 & 1.1 \\
\hline & & & D & 0 & 6.7 & 0 & 1.6 & 0.4 \\
\hline & \multirow{6}{*}{ M } & \multirow{2}{*}{ L } & v & 0.8 & 0.1 & 0.8 & 1.9 & 0 \\
\hline & & & D & 0.7 & 0.7 & 0.7 & 2.5 & 0.5 \\
\hline & & \multirow{2}{*}{ M } & v & 2 & 0 & 0.6 & 3.5 & 0 \\
\hline & & & D & 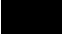 & & 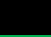 & 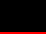 & \\
\hline & & \multirow{2}{*}{$\mathrm{H}$} & v & 0.7 & 1.2 & 0.2 & 2.6 & 0 \\
\hline & & & D & 0.4 & 2.8 & 0.1 & 0.9 & 0.1 \\
\hline & \multirow{6}{*}{$\mathrm{H}$} & \multirow{2}{*}{ L } & v & 1.4 & 0 & 0.4 & 1.5 & 0.1 \\
\hline & & & D & 2.4 & 0.2 & 0.6 & 4.7 & 0.1 \\
\hline & & \multirow{2}{*}{ M } & v & 0.9 & 0.4 & 0.3 & 1.3 & 0 \\
\hline & & & D & 3.5 & 0.8 & 28.2 & 3.3 & 0 \\
\hline & & \multirow{2}{*}{$\mathrm{H}$} & v & 0.9 & 1.1 & 0.3 & 0.9 & 0 \\
\hline & & & D & 2.4 & 1.2 & 0 & 0 & 0.2 \\
\hline \multirow{18}{*}{ M } & \multirow{6}{*}{$\mathrm{L}$} & \multirow{2}{*}{ L } & v & 0.2 & 0.6 & 0.2 & 2.8 & 0 \\
\hline & & & D & 2.1 & 2 & 2.1 & 2.6 & 3.2 \\
\hline & & $M$ & v & 0.2 & 0.2 & 0 & 2.1 & 0.1 \\
\hline & & w & D & 0.2 & 0.4 & 0 & 2 & 0.3 \\
\hline & & 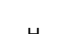 & v & & & & & \\
\hline & & , & D & & & & & \\
\hline & & t & v & 1.3 & 0.1 & 0.3 & 4.8 & 0.9 \\
\hline & & L & D & 0.9 & 0 & 0.2 & 2.4 & 1.6 \\
\hline & & & v & & & & & \\
\hline & . & in & D & & & & & \\
\hline & & H & v & & & & & \\
\hline & & T & D & & & & & \\
\hline & & t & v & 1.8 & 0 & 0.5 & 3.5 & 3 \\
\hline & & 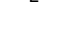 & D & 0 & 0 & 0 & 0 & 0 \\
\hline & $\mathrm{H}$ & $M$ & v & 10.4 & 10.6 & 1.7 & 4.5 & 0 \\
\hline & . & & D & 2.7 & 1.4 & 0 & 0 & 0.6 \\
\hline & & $\mathrm{H}$ & v & & & & & \\
\hline & & . & D & 3.2 & 1.5 & 1.3 & 1.7 & 0.3 \\
\hline & & 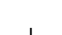 & v & 0.3 & 0.2 & 0 & 2.3 & 1 \\
\hline & & & D & 0.1 & 0 & 0 & 2.1 & 0.7 \\
\hline & & 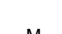 & v & 0.2 & 1.3 & 0 & 1.6 & 1.7 \\
\hline & & & D & & & & & \\
\hline & & $\mathrm{H}$ & $\mathrm{V}$ & & & & & \\
\hline & & 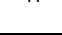 & D & & & & & \\
\hline & & I & V & & & & & \\
\hline & & 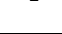 & D & & & & & \\
\hline . & $M$ & 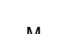 & V & & & & & \\
\hline+ & w & m & D & & & & & \\
\hline & & $\mathrm{H}$ & V & & & & & \\
\hline & & 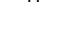 & D & & & & & \\
\hline & & & V & & & & & \\
\hline & & $\mathrm{L}$ & D & 5.4 & 0.3 & 0 & 0 & 3.9 \\
\hline & H & 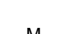 & V & & & & & \\
\hline & (1) & in & $\mathrm{D}$ & & & & & \\
\hline & & $\mathrm{H}$ & $\mathrm{V}$ & & & & & \\
\hline & & & D & & & & & \\
\hline
\end{tabular}


Table 8 Effect of changing input parameters on RE

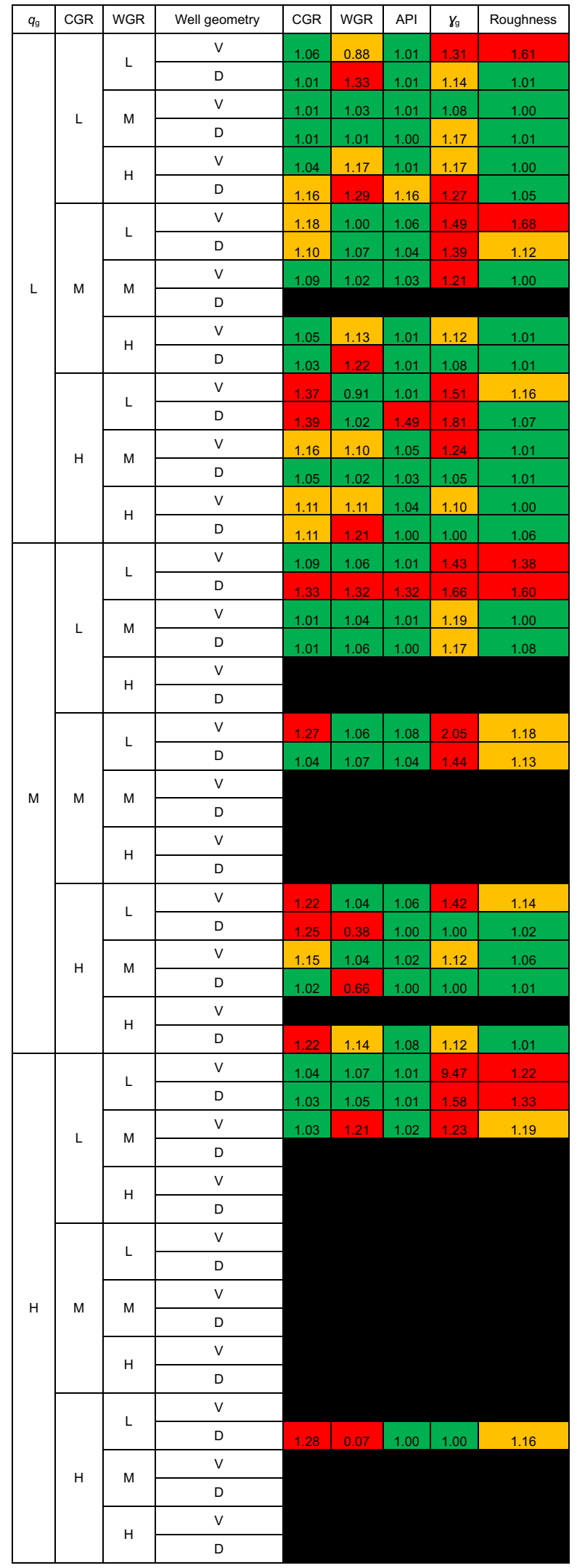

To make it easier to follow, a flow chart was built for each method used to study the effects of input parameters on the accuracy of calculated bottomhole pressure. Figure 11 shows the steps for studying the effect of input parameters on the selection of the best correlation used in the prediction of the pressure drop calculation. Figure 12 shows the steps for studying the effect of input parameters on the calculated absolute error based on the best correlation obtained from the base run. Figure 13 shows the steps for studying the effect of input parameters on the maximum absolute error from each correlation relative to actual data.

An average term between MAPD and RE called deviation index (DI) is used to conclude the effect of each parameter on the pressure drop calculation from the 2 nd and 3rd methods. If DI is less than 0.8 , the selected input parameter is considered to have low effect; however, the input parameter will have medium effect if the DI is between 0.8 and 1.6, and high effect if DI is higher than 1.6.

Figures 14 and 15 show the DI for the different input parameters for vertical and deviated wells.

It was found that gas specific gravity is the most effective parameter on the pressure drop calculations for both vertical and deviated gas wells. Gas specific gravity is one of the density indicators used in the calculation of both hydrostatic term and friction term of the general energy equation, so care should be taken in the usage of that term.

API of the condensate was found to have a low effect on most flow conditions because the gas is the main phase and the condensate is the associated phase. The effect of API increases to be a medium effect on pressure drop calculation in case of low gas rate with medium CGR for vertical wells due to the presence of condensate relative to the main phase of gas. However, for low gas rate with low WGR for deviated wells, tubing roughness was found to have medium effect in some flow conditions. For vertical wells, roughness has medium effect for low and high gas rates with low CGR and low WGR. For deviated wells, roughness has medium effect for low, medium and high gas rates with low WGR.

CGR was found to have medium effect for vertical wells, but the effect decreases to be low in case of low CGR values for all gas flow rates. Also, it was found that deviation for the wells increases the effect of CGR on the pressure drop calculations in case of high CGR for all gas flow rates. WGR was found to have low effect for vertical and deviated wells, and the effect increases to be medium in some cases of high CGR and WGR for low and medium gas flow rates. 
Table 9 Summary results for the effect of input parameters on the selection of the best correlation, MAPD and RE

\begin{tabular}{llccccc}
\hline Method & Parameter & CGR & WGR & API & $\gamma_{\mathrm{g}}$ & $\begin{array}{l}\text { Tubing } \\
\text { rough- } \\
\text { ness }\end{array}$ \\
\hline $\begin{array}{c}\text { Effect of input parameters on the } \\
\text { selection of the best correlation }\end{array}$ & High effect percentage (\%) & 9 & 9 & 3 & 25 & 9 \\
& Medium effect percentage (\%) & 16 & 13 & 16 & 25 & 32 \\
& Low effect percentage (\%) & 75 & 78 & 81 & 50 & 59 \\
Effect of input parameters on MAPD & High effect percentage (\%) & 28 & 16 & 9 & 56 & 9 \\
& Medium effect percentage (\%) & 38 & 39 & 25 & 31 & 28 \\
& Low effect percentage (\%) & 34 & 47 & 66 & 13 & 63 \\
Effect of inputparameters on RE & High effect percentage (\%) & 25 & 28 & 6 & 50 & 19 \\
& Medium effect percentage (\%) & 22 & 19 & 3 & 28 & 22 \\
& Low effect percentage (\%) & 53 & 53 & 91 & 22 & 59 \\
\hline
\end{tabular}

\section{Conclusions}

This work presents a comprehensive error analysis for the most important input parameters in multiphase flow correlations for gas wells using a large measured pressure data for wells with varying configurations and with wide range of gas production rate, CGR and WGR. Based on the results of the study, the following conclusions can be drawn:

1. Some input parameters to multiphase flow correlations have high effect on pressure drop calculations, and others have low effect. These investigated parameters (CGR, WGR, API, gas specific gravity and tubing roughness) usually carry some element of uncertainty and may have significant errors.

2. The selection of the best correlation is not affected by the error in input parameters.
3. Errors in gas specific gravity have the highest effect on the accuracy of the multiphase flow correlations for gas wells.

4. Error in estimating API of oil (or condensate) has minor effect on the pressure drop calculations for gas wells.

5. Errors in estimating CGR have low effect on the pressure drop calculations for deviated gas wells and increases for vertical.

6. WGR has a significant effect on the pressure drop calculations for deviated gas wells compared to vertical wells. Care should be taken in water production measurements in such cases.

7. Tubing roughness (which is difficult to obtain accurately) has low to medium effect for gas wells. The error in pressure drop calculations resulting from the error in tubing roughness becomes more significant for low CGR and WGR. 


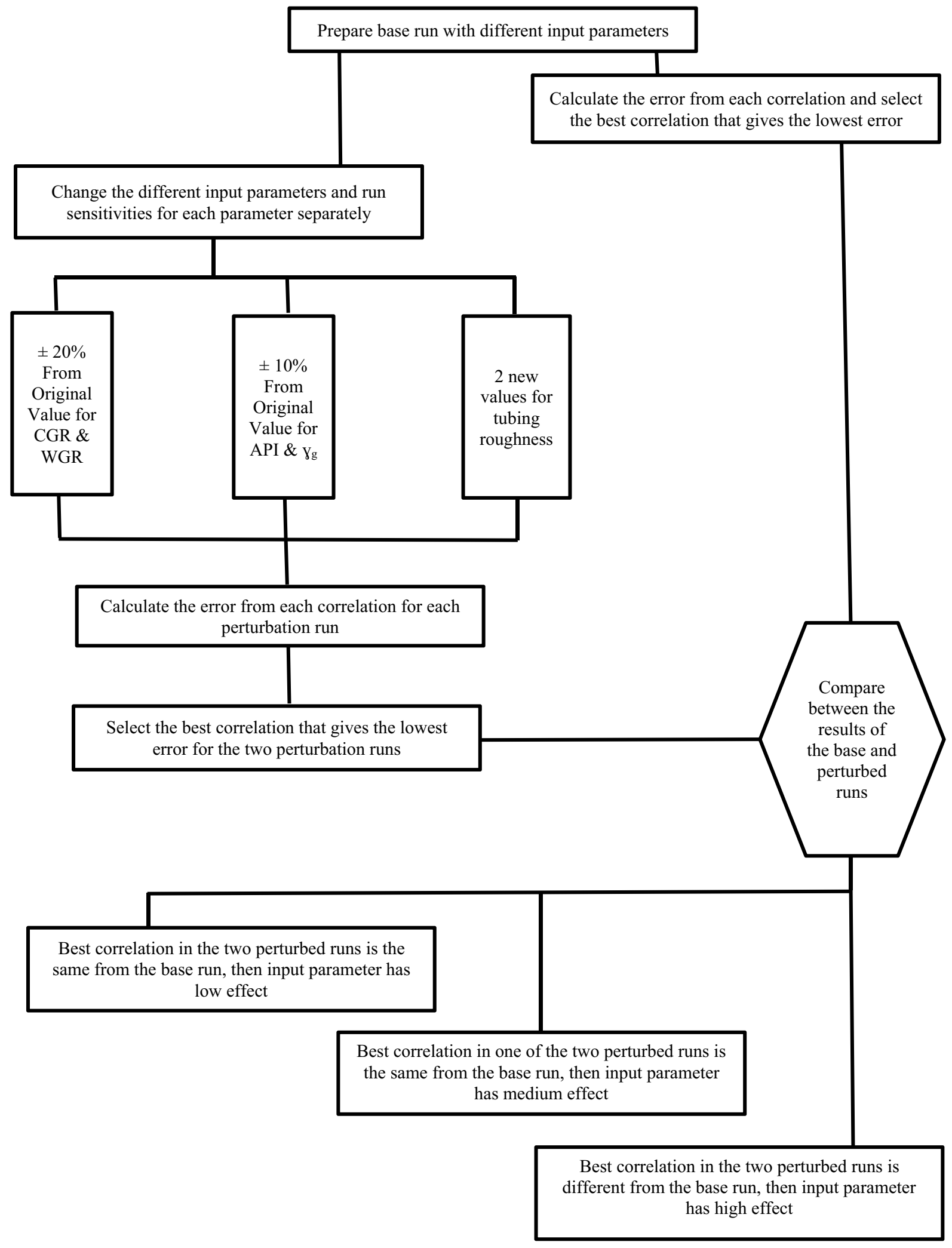

Fig. 11 Effect of input parameters on selection of the best correlation used in prediction of pressure drop 
Prepare base run with different input parameters

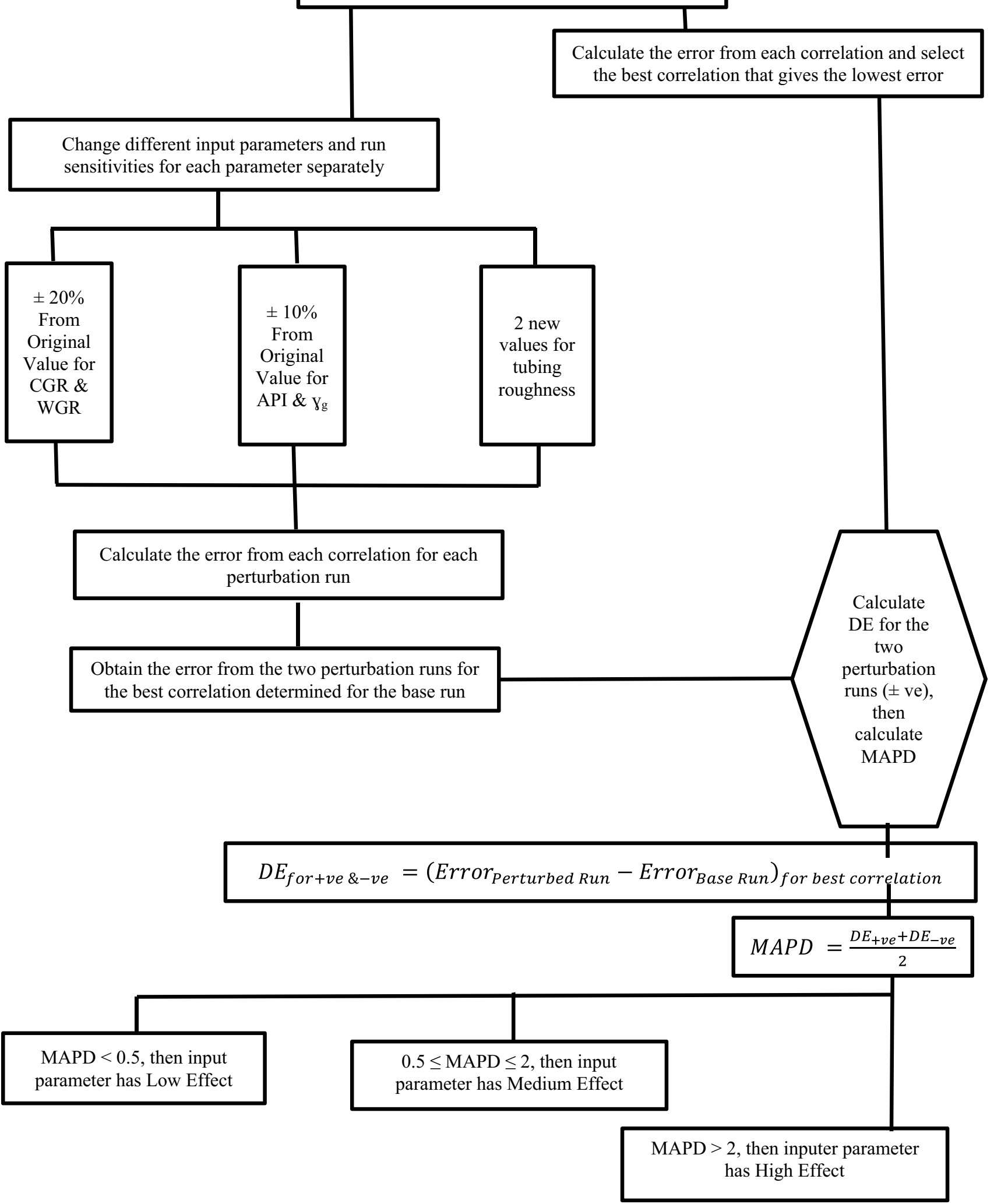

Fig. 12 Effect of input parameters on the calculated absolute error based on the best correlation obtained from the base run 


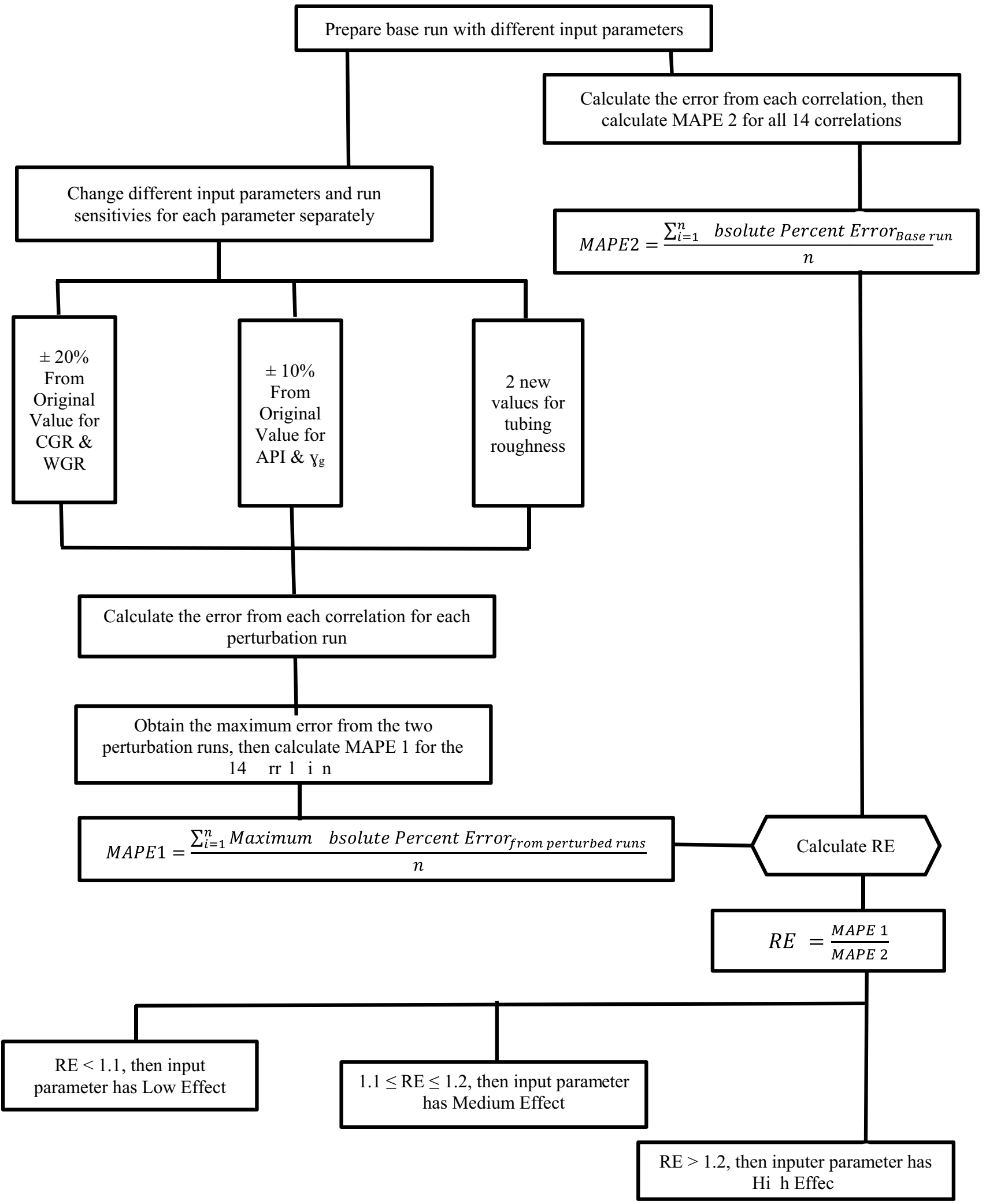

Fig. 13 Effect of input parameters on the maximum absolute error for each correlation relative to actual data 


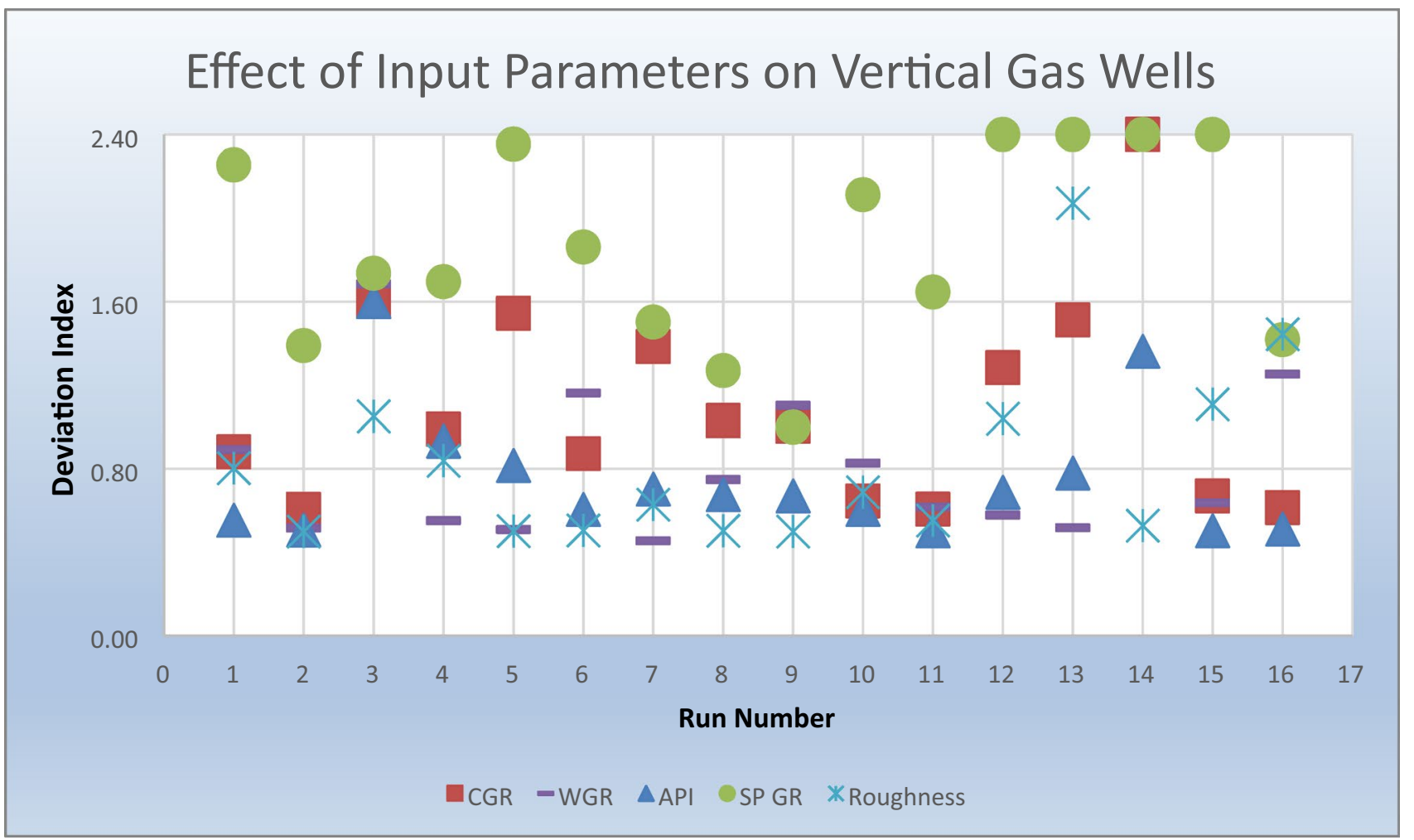

Fig. 14 Effect of different input parameters on vertical wells using deviation index method

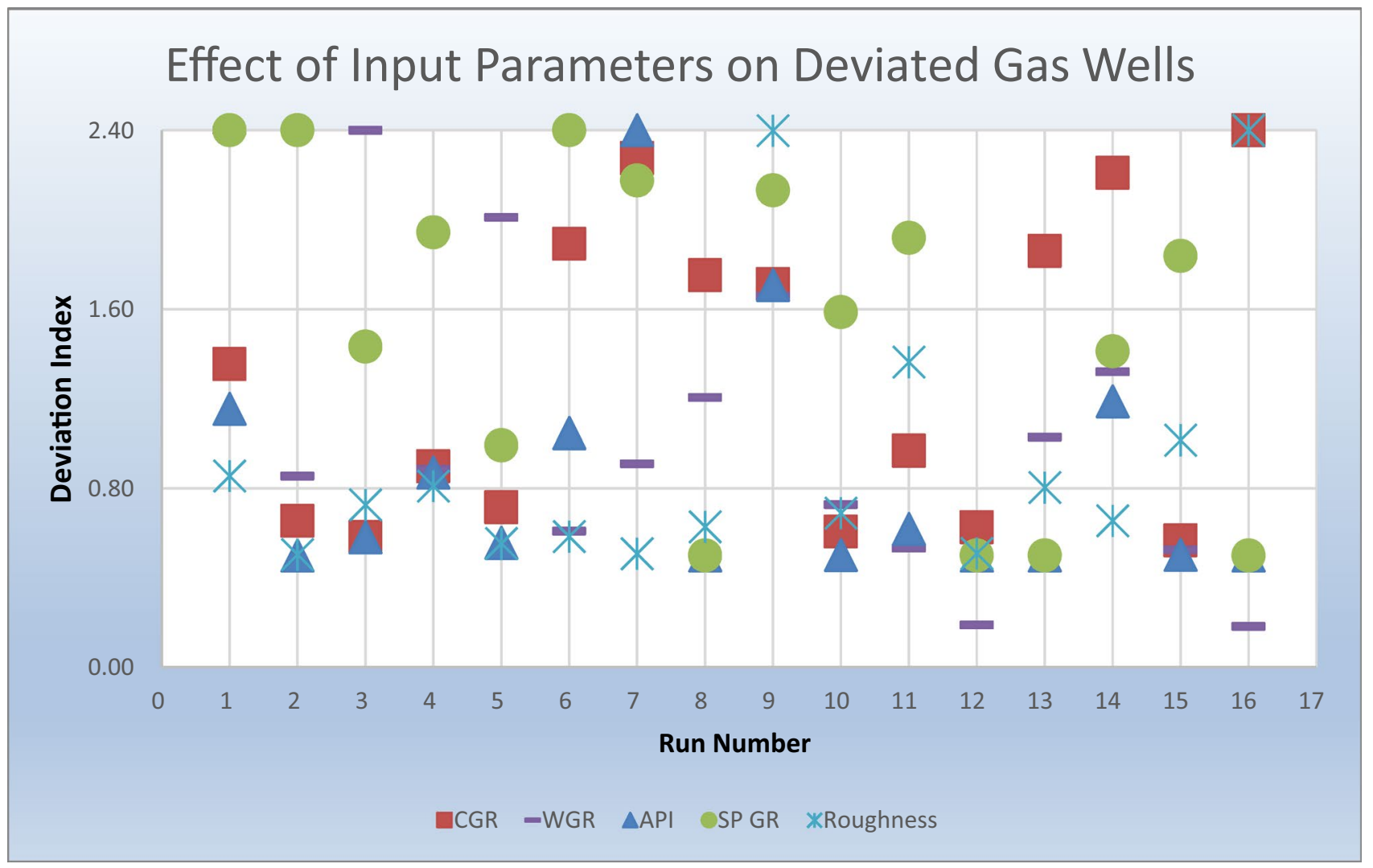

Fig. 15 Effect of different input parameters on deviated wells using deviation index method 
Open Access This article is licensed under a Creative Commons Attribution 4.0 International License, which permits use, sharing, adaptation, distribution and reproduction in any medium or format, as long as you give appropriate credit to the original author(s) and the source, provide a link to the Creative Commons licence, and indicate if changes were made. The images or other third party material in this article are included in the article's Creative Commons licence, unless indicated otherwise in a credit line to the material. If material is not included in the article's Creative Commons licence and your intended use is not permitted by statutory regulation or exceeds the permitted use, you will need to obtain permission directly from the copyright holder. To view a copy of this licence, visit http://creativecommons.org/licenses/by/4.0/.

\section{References}

Abd El-Moniem MA (2016) Evaluation and proper selection of multiphase flow correlations, MS Thesis, Cairo University, Egypt

Abd El-Moniem MA, El-Banbi AH (2015) Proper selection of multiphase flow correlations. In: North Africa technical conference and exhibition, SPE 175805-MS. https://doi.org/10.2118/17580 5-MS

Abd El-Moniem MA, El-Banbi AH (2018) Effect of data errors on multiphase flow correlations. In: SPE Kingdom of Saudi Arabia annual technical symposium and exhibition, SPE 192171-MS. https://doi.org/10.2118/192171-MS

Abd El-Moniem MA, El-Banbi AH (2018b) Development of an Expert System for Selection of Multiphase Flow Correlations. J Pet Explor Prod Technol 8(4):1473-1485. https://doi.org/10.1007/ s13202-018-0442-7

Ansari AM, Sylvester ND, Shoham O, Brill JP (1990) A comprehensive mechanistic model for upward two phase flow in Wellbores. In: 65th annual technical conference and exhibition, pp 151-165. SPE 20630-MS. https://doi.org/10.2118/20630-MS

Ashiem H (1986) MONA, an accurate two phase well flow model based on phase slippage. SPE Prod Eng. https://doi.org/10.2118/12989 -PA

Aziz K, Govier GW (1972) Pressure drop in wells producing oil and gas. J Can Pet 11:38-48. https://doi.org/10.2118/72-03-04

Baxendell PB, Thomas R (1961) The calculation of pressure gradients in high-rate flowing wells. J Pet Technol 13(10):1023-1028. https ://doi.org/10.2118/2-PA

Beggs DH, Brill JP (1973) A study of two-phase flow in inclined pipes. J Pet Technol 25(05):607-617. https://doi.org/10.2118/4007-PA

Chierici GL, Ciucci GM, Sclocchi G (1974) Two-phase vertical flow in oil wells-prediction of pressure drop. J Pet Technol 26(08):927938. https://doi.org/10.2118/4316-PA

Duns H, Ros NCJ (1963) Vertical flow of gas and liquid mixtures in wells. Section II, paper 22-PD 6. In: Proceedings of sixth world petroleum congress, pp 451-465. WPC-10132
Fancher GH, Brown KE (1963) Prediction of pressure gradients for multiphase flow in tubing. Soc Pet Eng J. https://doi. org/10.2118/440-PA

Gould TL, Tek MR, Katz DK (1963) Two phase flow through vertical, inclined, or curved pipe. J Pet Technol 26:915-926

Gray HE (1978) Vertical flow correlation in gas wells, User's manual for API 14B surface controlled subsurface safety valve sizing computer program, 2nd edn, (appendix B), American Petroleum Institute, Dallas, TX, June

Hagedorn AR, Brown KE (1964) The effect of liquid viscosity in twophase vertical flow. J Pet Technol 16(02):203-210. https://doi. org/10.2118/733-PA

Hagedorn AR, Brown KE (1965) Experimental study of pressure gradients occurring during continuous two-phase flow in smalldiameter vertical conduits. J Pet Technol 17(04):475-484. https ://doi.org/10.2118/940-PA

Hill TJ, Wood DG (1994) Slug flow: occurrence, consequences, and prediction. In: SPE 27960 presented at the University of Tulsa petroleum engineering symposium, OK, U.S.A., 29-31 August, pp 53-62

Kleyweg D, Tiemann WD, Dalziel SG (1983) Gas lift optimization in the claymore field. In: Offshore Europe. SPE 11885-MS. https:// doi.org/10.2118/11885-MS

Minami K, Brill JP (1987) Liquid holdup in wet-gas pipelines. SPE Prod Eng 2(01):36-44. https://doi.org/10.2118/14535-PA

Mukherjee H, Brill JP (1983) Liquid holdup correlations for inclined two-phase flow. J Pet Technol 35(05):1003-1008. https://doi. org/10.2118/10923-PA

Orkiszewski J (1967) Predicting two-phase pressure drops in vertical pipe. J Pet Technol 19(06):829-838. https://doi. org/10.2118/1546-PA

Peffer JW, Miller MA, Hill AD (1988) An improved method for calculating bottomhole pressures in flowing gas wells with liquid present. SPE Prod Eng 3(04):643-655. https://doi.org/10.2118/15655 -PA

Poettmann FH, Carpenter PJ (1952) The multiphase flow of gas, oil and water through vertical flow string with the application of the design of gas lift installation. American petroleum institute. API-52-257

Prosper Software Help Manual (2013) Petroleum Experts Ltd, Edinburgh, UK

Reinicke KM, Remer RJ (1987) Comparison of measured and predicted pressure drops in tubing for high-water-cut gas wells. SPE Prod Eng 2(03):165-177. https://doi.org/10.2118/13279-PA

Publisher's Note Springer Nature remains neutral with regard to jurisdictional claims in published maps and institutional affiliations. 